\title{
Application of Fuzzy Logic Sugeno Methods for Diagnosis Typhoid Fever Disease and Dengue Hemorrhagic Fever
}

\author{
Iwan Santosa ${ }^{1}$, Eza Rahmanita ${ }^{2}$, Tri Qurratul A'Yuni ${ }^{3}$, Triuli Novianti ${ }^{4}$ \\ \{iwan@trunojoyo.ac.id $\left.{ }^{1}\right\}$ \\ Faculty of Engineering, University of Trunojoyo Madura, Jalan Raya Telang, PO BOX 02 Kamal, \\ Bangkalan - $69162^{123}$, Faculty of Engineering, Muhammadiyah University of Surabaya, \\ J1. Sutorejo No. 59, Surabaya $-60113^{4}$
}

\begin{abstract}
Typhoid fever and dengue hemorrhagic fever are common diseases in Indonesia. Typhoid fever is caused by bacteria while dengue hemorrhagic fever is caused by the dengue virus. Both of these diseases are often misdiagnosed because they have the same symptoms as other diseases so that they can cause the high rate of death. Therefore, it takes an expert system as a tool to diagnose typhoid fever and dengue hemorrhagic fever to be handled quickly and precisely. The Expert system built by using the Sugeno Fuzzy Logic method. It expected to be a solution to facilitate the public to diagnose typhoid fever and dengue hemorrhagic fever based on the symptoms and get treatment solutions. This study has produced expert system to diagnose typhoid fever and dengue hemorrhagic Fever. It had been tested 86 cases of data with an accuracy value is $80.2 \%$.
\end{abstract}

Keywords: typhoid and dengue hemorrhagic fever, expert system, fuzzy sugeno.

\section{Introduction}

Typhoid fever and DHF (Dengue Hemorrhagic Fever) are common diseases in Indonesia. Typhoid fever is a disease caused by Salmonella Enterica bacteria, how to spread it through vomit, urine and feces from patients who are then passively carried by flies, while dengue hemorrhagic fever is an acute febrile disease caused by the dengue virus that enters the human blood circulation through bites Aedes Aegypti and Aedes Albopictu mosquitoes [1], the mortality rate in this disease is still relatively high. Typhoid fever is better treated when diagnosed earlier, but can cause other medical complications such as intestinal bleeding if not treated immediately. This event requires major surgery and can even cause death[2] . One of the causes of high rates of death is the difficulty of obtaining a temporary diagnosis.

Typhoid Fever and Dengue Hemorrhagic Fever are also often misdiagnosed because they have the same symptoms as other diseases, which are characterized by high fever [1]. Dengue hemorrhagic fever is an indicator that is used to see the degree of public health in Pamekasan district (indonesia) because in 2016 there were 594 cases, while typhoid fever was categorized as the 10 biggest diseases of various other diseases based on data obtained at the hospital of Dr. RSUD. H. Slamet Martodirdjo.

Patients with typhoid fever and dengue hemorrhagic fever, each year have increased. This disease can affect children and adults. For patients with typhoid fever and dengue hemorrhagic

ICCSET 2018, October 25-26, Kudus, Indonesia

Copyright (C) 2018 EAI

DOI 10.4108/eai.24-10-2018.2280495 
fever if not given treatment immediately can result in death [3]. Therefore, the system as a tool for diagnosing typhoid fever and dengue hemorrhagic fever cases is needed to prevent case handling errors and reduce mortality. The system used as a tool is an expert system.

The expert system built will use the Sugeno Method of Fuzzy Logic modeling techniques. Fuzzy logic is very flexible and has a very simple mathematical concept that is easy to understand. Fuzzy logic modeling techniques consist of Tsukamoto, Mamdani and Sugeno. In the Tsukamoto Method, each consequence of the rules in the form of IF-THEN must be represented by a fuzzy set with a monotonous membership function. The output of the inference from each rule is a regular set (crisp) which is determined based on the $\alpha$-predicate (fire strength) [3]. In the Mamdani Method, the implication function used is Min, while in conducting fuzzy system inference the Max method is used. This method is known as the minmax method. The output inference is in the form of fuzzy numbers so it must be determined a crisp value obtained by taking the center point of the fuzzy region [4]. While the Sugeno method, a method that corrects weaknesses that are owned by pure fuzzy. The implication function used is function min. inference output (consequent) produced is not in the form of fuzzy set but is linear or constant [5], the sugeno method has a smaller error rate compared to the Tsukamoto method [6], has a better processing time because it has a constant output dependent variable [7].

The expert system produced with fuzzy logic sugeno method is expected to help the community to diagnose typhoid fever or dengue hemorrhagic fever based on the causes or symptoms experienced and can provide treatment solutions.

\section{Research Method}

Research methodology will be explained using Flowchart. This is a chart with a symbol that describes a process in detail and the relationship between a process and other processes. In this expert system there are four flowcharts that each flowchart has a different process sequence. This flowchart describes the whole research process that has been carried out. the process for the process will be explained as below.

a) Start Start the system.

b) Enter the variable value Fuzzy inference systems diagnose Dengue Hemorrhagic and Typhoid Fever are made with 5 input variables and 16 questions, input variables consist of Fever, Muscle Pain and Joints, Digestive Disorders, Manifestation of Bleeding and Skin Conditions. In each question if the answer "yes" is given a weight of 2 if "No" is given a weight of 1 , but because the range of weight values on fuzzy logic is between 0 to 1 , the weight value of each answer will be summed based on the variable then it will be divided by 100 , so maximum weight of 1 is reached. Then it will be processed with the sugeno method fuzzy logic.

c) Determine the degree of membership

Each system variable in the fuzzy set is determined by the degree of membership for each linguistic attribute. Where the degree of membership becomes a value in the fuzzy set using Trapezoid curve representation. Figure 2 shows a trapezoid curve representation. 


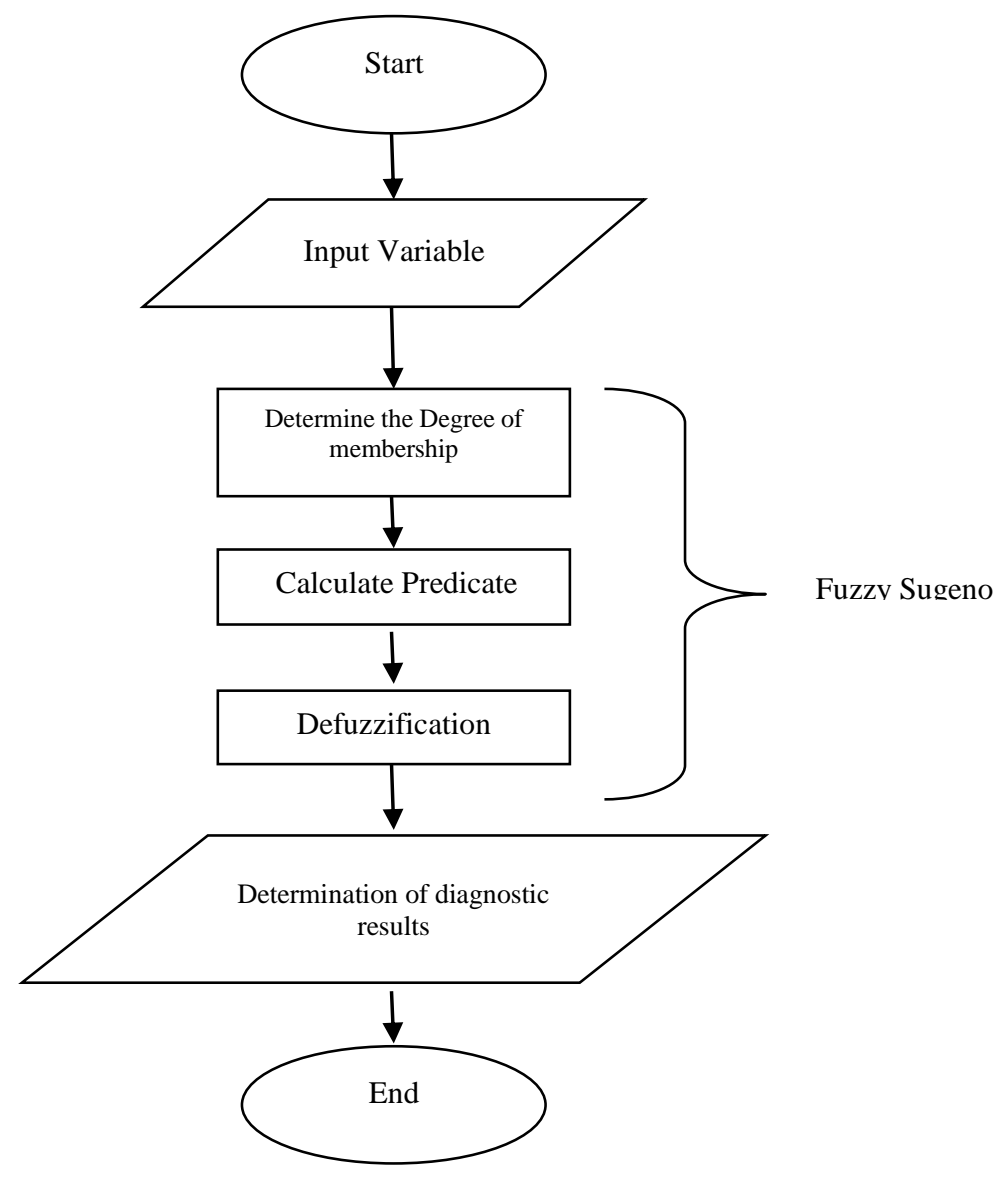

Fig. 1. Flowchart System. 


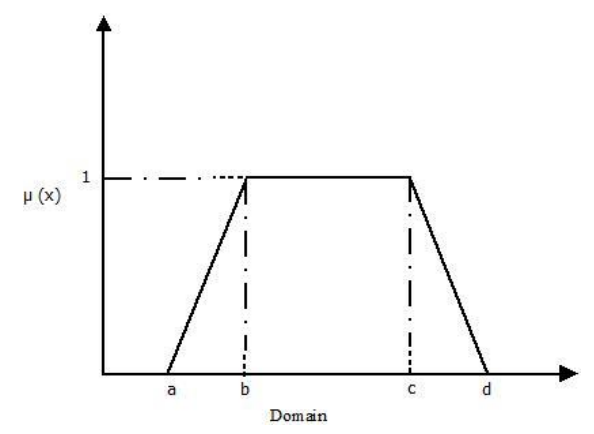

Fig. 2. Trapezoid curve Representation[8].

Membership function of this type[8][9]:

$$
\mu f(x)=\begin{array}{cc}
0 ; & x \leq a \text { atau } x \geq d \\
\frac{(x-a)}{(b-a)} ; & a \leq x \leq b \\
1 ; & b \leq x \leq c \\
\left(\frac{(d-x)}{(d-c)} ;\right) & x \geq d
\end{array}
$$

d) Calculating rule predicate $(\alpha)$

Variables that have been included in the fuzzy set are formed by the rules obtained by combining each variable with one variable with each linguistic attribute to obtain 32 rules. The rules that have been obtained will be calculated the predicate value of the rules with the implication process. In the sugeno method the process of implication is carried out by min operation. The rule predicate is obtained by taking the minimum value of the one variable membership degree with the other variable.

e) Defuzzification

After calculating all predicate rules that have been determined, the defuzzification value can be determined. In the sugeno model the defuzzification value is obtained by calculating the Weight Average (WA)[10].

$$
W A=\frac{\alpha 1 z 1+\alpha 2 z 2+\cdots+\alpha N z N}{\alpha 1+\alpha 2+\cdots+\alpha N}
$$

f) Determination of diagnostic results

The process of determining the results of a diagnosis will be based on the level of a diagnostic decision. 
Table 2. Calculation of Rules Predicate.

\begin{tabular}{cc}
\hline Decision Level Diagnosis & Diagnosis \\
\hline $0-0,8$ & Not Infected \\
$0,7-0,9$ & Typhoid Fever \\
$0,8-1$ & DBD \\
\hline
\end{tabular}

g) Diagnosis results

The diagnosis is the final result of the consultation conducted by the patient. the output produced is the name of the disease and the way it is treated.

h) Finish

The system is complete.

\section{$3 \quad$ Result and Discussion}

Accuracy testing is done by comparing the system predictions with expert predictions contained in the medical record, whether the prediction of the disease in the system is correct or an error occurs. Then the correct data will be added. To calculate the percentage of data according to the expert or accuracy, calculated using the formula (3)[11]:

$$
\% \text { accuracy }=\frac{\text { correct data }}{\text { The amount of test data }} \times 100 \%
$$

For testing the accuracy of this application that is comparing the system predictions with expert predictions contained in the medical record, whether the prediction of the disease in the system is correct or an error occurs. In the accuracy test using 86 patient data with the input symptoms experienced by each patient.

Table 4. Accuracy Test Data.

\begin{tabular}{ccccc}
\hline No & Name & System Prediction & Expert Prediction & Result \\
\hline 1 & A & DBD & DBD & True \\
2 & B & TYPHOID & TYPHOID & True \\
3 & C & DBD & TYPHOID & False \\
4 & D & TYPHOID & DBD & False \\
5 & E & DBD & TYPHOID & False \\
6 & F & TYPHOID & TYPHOID & True \\
7 & G & TYPHOID & TYPHOID & True \\
$\ldots$ & $\ldots$ & $\ldots$ & $\ldots$ & $\ldots$ \\
71 & BS & DBD & DBD & True \\
72 & BT & TYPHOID & TYPHOID & True \\
73 & BU & DBD & DBD & True \\
74 & BV & DBD & DBD & True \\
75 & BW & DBD & DBD & True \\
76 & BX & TYPHOID & DBD & False \\
77 & BY & DBD & DBD & True \\
78 & BZ & TYPHOID & TYPHOID & True \\
79 & CA & DBD & DBD & True \\
\hline
\end{tabular}




\begin{tabular}{lllll}
\hline 80 & CB & DBD & DBD & True \\
81 & CC & DBD & DBD & True \\
82 & CD & DBD & DBD & True \\
83 & CE & DBD & DBD & True \\
84 & CF & DBD & DBD & True \\
85 & CG & DBD & DBD & True \\
86 & CH & DBD & DBD & True \\
\hline
\end{tabular}

From the table of accuracy test data, obtained the results of the comparison between the prediction of the system with expert predictions derived from the calculation of Sugeno fuzzy logic method with expert predictions from medical record data. From 86 patient data, the results obtained Check 69 correct data and 17 incorrect data. From the above calculation using formula(3), the expert system for diagnosing typhoid fever and dengue hemorrhagic fever with the Sugeno fuzzy logic method has a percentage of accuracy test of $80.2 \%$.

\section{Conclusion}

From the results of the design, implementation and testing of expert system applications to diagnose typhoid fever and dengue hemorrhagic fever, it can be concluded that from the 86 cases of data trials, the results of accuracy testing between the prediction of the system with expert predection obtained $80.2 \%$ truth.

\section{References}

[1] P. M. . Wijaya, B., "Design of Expert System for Diagnosing Typhoid Fever and Dengue Hemorrhagic Fever with Forward Chaining Method," Ultimatics, vol. IV, no. 1, pp. 17-23, 2012.

[2] A. I. Celestine O.N.N., Abdurrahman U. F. N., "Circulation in Computer Science," vol. 2, no. 9, pp. 13-16, 2017.

[3] N. D. dan K. Waluyo., "Expert System for Diagnosing DHF and Typhoid Fever With Fuzzy Tsukamoto Method," 2016.

[4] Y. Yudihartanti, "Comparative Analysis of Fuzzy Mamdani and Sugeno Methods. Progresif," vol. 7, no. 2, pp. 731-780, 2011.

[5] M. . Rohman, "Supporting System for New Student Acceptance Decisions Using Sugeno Model Fuzzy Logic Method," J. Sarj. Tek. Inform., vol. 1, no. 1, pp. 1-12, 2014.

[6] A. . Cahyono, "SPK Comparative Analysis Using Fuzzy Sugeno and Tsukamoto Methods," 2017.

[7] Y. Wang, Y dan Chen, "A Comparison of Mamdani and Sugeno Fuzzy Inference Systems for Traffic Flow Prediction," J. Comput., vol. 9, no. 1, pp. 12-21, 2014.

[8] L. D. Xiao Z., Xia S., Gong K., "The trapezoidal fuzzy soft set and its application in MCDM. Applied Mathematical Modelling," ScienceDirect, vol. 36, no. 12, pp. 5844-5855, 2012.

[9] I. Maleki, I., Ebrahimi, L., Jodati, S., Ramesh, "Analysis Of Software Cost Estimation Using Fuzzy Logic,” Int. J. Found. Comput. Sci. Technol., vol. 4, no. 3, 2014.

[10] G. Rebrovs, O.U., Kulesova, "Comparative Analysis of Fuzzy Set Defuzzification Methods in the Context of Ecological Risk Assessment," Inf. Technol. Manag. Sci., vol. 20, pp. 25-29, 2017.

[11] S. Syahputra, D., Tulus, "The Accuracy Of Fuzzy Sugeno Method With Antropometry On Determination Natural Patient Status. IOP Conf. Series,” J. Phys. Conf. Ser. 930 012022, 2017. 